\title{
Thermal stability and grain growth behavior of mechanically alloyed nanocrystalline $\mathrm{Fe}-\mathrm{Cu}$ alloys
}

\author{
J. Eckert, J. C. Holzer, and W. L. Johnson \\ California Institute of Technology, W. M. Keck Laboratory of Engineering Materials 138-78, Pasadena, \\ California 91125
}

(Received 24 June 1992; accepted for publication 24 September 1992)

\begin{abstract}
$\mathrm{X}$-ray diffraction, transmission electron microscopy, and differential scanning calorimetry were used to study the thermal stability of highly supersaturated nanocrystalline $\mathrm{Fe}_{x} \mathrm{Cu}_{100-x}$ alloys $(10<x<95)$ synthesized by mechanical alloying. Alloys with $x<60$ exhibit single-phase fcc structure while single-phase bcc alloys form for $x>80$. For $60 \leqslant x \leqslant 80 \mathrm{fcc}$ and bcc phases coexist. Heating to elevated temperatures leads to structural relaxation, phase separation, and grain growth of the metastable nanocrystalline solid solutions. Single-phase fcc and bcc alloys undergo significant strain release but no appreciable grain growth prior to phase separation. After phase separation pronounced grain growth sets in. In contrast, samples in the two-phase region show some grain growth and significant chemical redistribution even at low temperatures. The phase separation of single-phase fcc and bcc alloys proceeds via different mechanisms: fcc solid solutions decompose by forming small $\mathrm{Fe}$ precipitates, while demixing in bcc alloys starts by segregation of $\mathrm{Cu}$ atoms to bcc grain boundaries before nucleation of $\mathrm{Cu}$ precipitates. These results show that the stability and grain growth behavior of nanocrystalline alloys is strongly affected by the microstructure of the material.
\end{abstract}

\section{INTRODUCTION}

The synthesis of metastable phases by mechanical alloying/ball milling has been studied extensively in recent years, revealing that this technique is a versatile tool for producing materials far from thermodynamic equilibrium. ${ }^{1-3}$ In particular, it has been shown that nanocrystalline metals and alloys can be obtained by heavy mechanical deformation during mechanical attrition. ${ }^{3-6}$ In the early stages of milling, the deformation is localized in dislocation cell structures within shear bands. ${ }^{4}$ Upon further deformation, the crystal lattice breaks into nanometer-sized grains within these shear bands, leading ultimately to a nanocrystalline powder with completely random orientation of neighboring grains separated by high-angle grain boundaries. Thus, the mechanical attrition method produces a nanocrystalline structure by creating grain boundaries within conventional polycrystals. Since the nanocrystalline structure is a nonequilibrium state and the grain coarsen at elevated temperatures, the thermal stability of such materials is an important subject with respect to possible applications.

In previous articles we reported on the progress of alloying, the formation ranges, and the compositional dependence of the grain size in nanocrystalline $\mathrm{Fe}_{x} \mathrm{Cu}_{100-x}$ alloys $(10<x<95)$ synthesized by mechanical alloying of elemental $\mathrm{Fe}$ and $\mathrm{Cu}^{7-9}$. Although $\mathrm{Fe}$ and $\mathrm{Cu}$ exhibit only vanishingly small mutual solid solubilities under equilibrium conditions, ${ }^{10}$ single-phase fcc alloys with $x<60$ and single-phase bcc alloys with $x>80$ can be synthesized by mechanical alloying. For $60<x<80$ both phases coexist. These results are consistent with the formation of supersaturated $\mathrm{Fe}-\mathrm{Cu}$ alloys reported by other authors utilizing thermal evaporation, ${ }^{11,12}$ liquid quenching, ${ }^{13,14}$ ion implantation, ${ }^{15}$ and mechanical alloying. ${ }^{16,17}$
In the present investigation we present a detailed study of the thermal stability of the metastable $\mathrm{Fe}-\mathrm{Cu}$ solid solutions. Since the $\mathrm{Fe}-\mathrm{Cu}$ system has a large positive enthalpy of mixing, ${ }^{18}$ there is a strong tendency for decomposition of the supersaturated solid solutions at elevated temperatures. It is of interest to study this phase separation and its effect on the grain growth characteristics of these nanocrystalline alloys. Another important issue is to compare the stability of single-phase powders and two-phase mixtures to see how the nucleation of a second phase affects the thermal stability of these materials. It will be shown that for the metastable nanocrystalline powders both phase scparation and grain growth occur at elevated temperatures; however, single-phase fcc and bcc alloys are more stable against microstructural changes than twophase mixtures. This will be discussed with respect to grain-boundary segregation and differences in the nucleation of a second phase, showing that chemical and structural homogeneity play an important role for the stability of these nanocrystalline solid solutions.

\section{EXPERIMENTAL METHODS}

Elemental $\mathrm{Fe}$ and $\mathrm{Cu}$ powders (99.9\% purity) with particle sizes of $\leqslant 100 \mu \mathrm{m}$ were mixed to give the desired average composition and sealed in a vial under an argon atmosphere. Mechanical alloying was performed in a Spex 8000 laboratory mill using hardened steel balls and vial with a ball-to-powder weight ratio of $4: 1$. The vial temperature was held below $375 \mathrm{~K}$ during the experiments by air cooling. Wavelength-dispersive $\mathrm{x}$-ray analysis (WDX) using a JEOL Superprobe 733 operated at $15 \mathrm{kV}$ reveals that less than 2 at. \% additional $\mathrm{Fe}$ due to wear debris from the steel balls and vial are introduced into the powders even after $24 \mathrm{~h}$ of milling. 
TABLE I. Lattice structure, average grain size $d$, and rms atomic-level strain $\left\langle e^{2}\right\rangle^{1 / 2}$ for as-milled $\mathrm{Fe}_{x} \mathrm{Cu}_{100-x}$ solid solutions after $24 \mathrm{~h}$ of mechanical alloying. ${ }^{\mathrm{a}}$

\begin{tabular}{lccccc}
\hline \hline$x$ & Structure & $d_{\mathrm{fcc}}(\mathrm{nm})$ & $d_{\mathrm{bcc}}(\mathrm{nm})$ & $\left\langle e^{2}\right\rangle^{1 / 2} \mathrm{fcc}(\%)$ & $\left\langle e^{2}\right\rangle^{1 / 2}$ bcc $(\%)$ \\
\hline 0 & $\mathrm{fcc}$ & 20 & $\ldots$ & 0.20 & $\ldots$ \\
10 & $\mathrm{fcc}$ & 17 & $\ldots$ & 0.17 & $\ldots$ \\
20 & $\mathrm{fcc}$ & 14 & $\ldots$ & 0.18 & $\ldots$ \\
30 & $\mathrm{fcc}$ & 13 & $\ldots$ & 0.33 & $\ldots$ \\
40 & $\mathrm{fcc}$ & 11 & $\ldots$ & 0.18 & $\ldots$ \\
45 & $\mathrm{fcc}$ & 10 & $\ldots$ & 0.24 & $\ldots$ \\
50 & $\mathrm{fcc}$ & 9 & $\ldots$ & 0.49 & $\ldots$ \\
55 & $\mathrm{fcc}$ & 10 & $\ldots$ & 0.45 & $\ldots$ \\
& & & $\ldots$ & 0.44 & \\
60 & $\mathrm{fcc}+\mathrm{bcc}$ & 9 & $\ldots$ & 0.29 & 1.6 \\
65 & $\mathrm{fcc}+\mathrm{bcc}$ & 6 & 2 & 0.41 & 0.64 \\
70 & $\mathrm{fcc}+\mathrm{bcc}$ & 8 & 2 & 0.45 & 0.84 \\
75 & $\mathrm{fcc}+\mathrm{bcc}$ & 8 & 4 & $\ldots$ & 0.69 \\
80 & $\mathrm{fcc}+\mathrm{bcc}$ & 8 & 5 & $\ldots$ & 0.67 \\
85 & $\mathrm{bcc}$ & $\ldots$ & 5 & $\ldots$ & 0.60 \\
90 & $\mathrm{bcc}$ & $\ldots$ & 6 & $\ldots$ & 0.62 \\
95 & $\mathrm{bcc}$ & $\ldots$ & 5 & $\ldots$ & 0.65 \\
100 & $\mathrm{bcc}$ & $\ldots$ & 6 & $\ldots$ & \\
\hline \hline
\end{tabular}

asee Refs. 7-9.

X-ray-diffraction patterns were taken with a Norelco diffractometer in step-scanning mode using Ni-filtered $\mathrm{Cu}$ $K \alpha$ radiation $(\lambda=0.1542 \mathrm{~nm})$, and a Gencral Elcetric diffractometer using Co- $K \alpha$ radiation $(\lambda=0.1789 \mathrm{~nm})$ and an INEL CPS 120 position-sensitive detector. For the statistical quality of our data, we believe that the detection limit for either fcc or bcc phases was $0.5 \mathrm{vol} \%$. Transmission electron microscopy (TEM) was done with a Philips EM 430 microscope operated at $300 \mathrm{kV}$. The TEM samples were prepared by mixing the powders with epoxy and slicing into $20-50-n m$-thick sections by diamond-knife microtomy. Thermal analysis was performed in a differential scanning calorimeter (Perkin-Elmer DSC 4) at a heating rate of $20 \mathrm{~K} / \mathrm{min}$ under flowing argon. After each scan a baseline scan was carried out without changing the sample configuration.

\section{RESULTS}

Table I summarizes the microstructural data for the mechanically alloyed $\mathrm{Fe}_{x} \mathrm{Cu}_{100-x}$ samples used for this investigation (for further details see Refs. 7-9). Powders with $x<60$ and $x>80$ exhibit single-phase fcc and bcc structures, respectively. For $60 \leqslant x \leqslant 80$ both phases coexist even after extended milling. To determine the grain size and the atomic-level strain of the mechanically alloyed powders we analyzed the full width at half-maximum (FWHM) of x-ray-diffraction peaks as a function of diffraction angle. Converting the diffraction angle $2 \theta$ to the reciprocal space variable $s=2 \sin \Theta / \lambda$, one can show that the peak broadening due to size effects is independent of $s$, while the strain broadening is proportional to $s .{ }^{6,19}$ Thus, the dependence of the measured FWHM on $s$, determined after correcting for $K \alpha_{2}$ intensity and instrumental broadening contributions, enables the grain size $d$ and the rms atomic-level strain $\left\langle e^{2}\right\rangle^{1 / 2}$ to be determined. ${ }^{6,19}$ Although

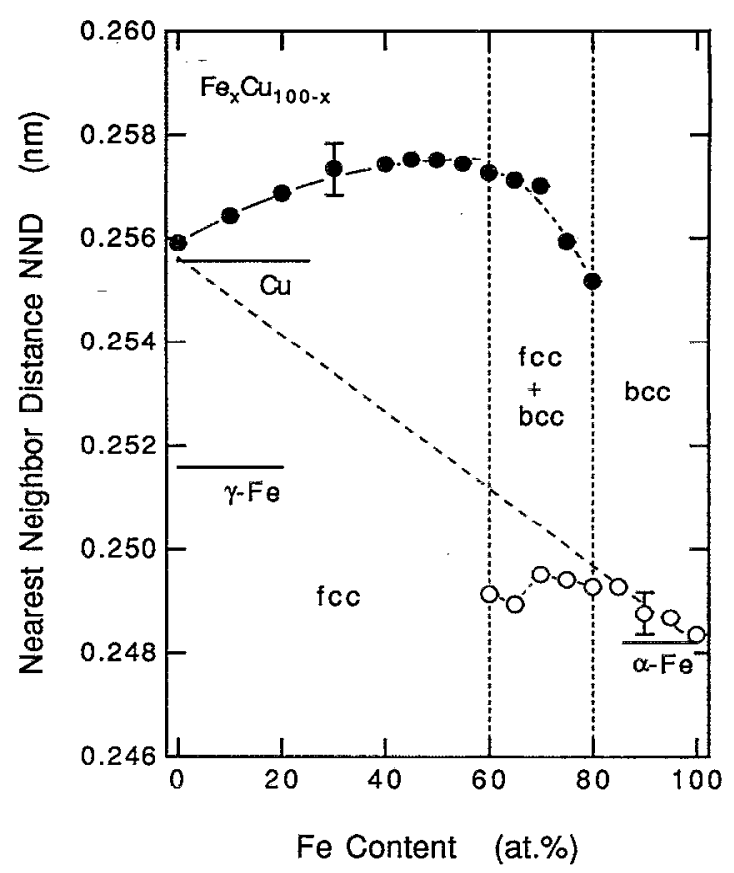

FIG. 1. Compositional dependence of the nearest-neighbor distance (NND) for as-milled $\mathrm{Fe}_{x} \mathrm{Cu}_{100-x}$ alloys after $24 \mathrm{~h}$ of mechanical alloying $[(-)$ fcc phase and $(O)$ bcc phase]. The dashed line refers to Vegard's law.

semiquantitative, this approach is adequate for comparing samples of different compositions or annealing treatments. The average grain sizes of the as-milled $\mathrm{Fe}-\mathrm{Cu}$ solid solutions vary between 2 and $20 \mathrm{~nm}$ for samples with different compositions (Table I). These values agree well with the grain sizes determined from TEM images of the powder and are consistent with the grain sizes reported for other ball-milled nanocrystalline metals and alloys, ${ }^{3-6}$ and with data reported for $\mathrm{Fe}-\mathrm{Cu}$ alloys prepared by mechanical alloying ${ }^{16,17}$ and inert gas condensation ${ }^{20}$ (for further details see Refs. 7-9). The atomic-level strains determined from $x$-ray diffraction range from $0.2 \%-0.5 \%$ for fcc alloys to $0.6 \%-1.6 \%$ for bec alloys (Table I), which is comparable to the values found for other ball-milled metals and alloys. $^{4-6}$

Figure 1 shows the compositional dependence of the nearest-neighbor distance (NND) for fcc and bcc solid solutions in $24 \mathrm{~h}$ milled samples. For single-phase fcc alloys $(x<60)$ the NND increases continuously from the value of pure $\mathrm{Cu}$ with increasing $\mathrm{Fe}$ content. For singlephase bcc samples $(x>80)$ the NND increases with increasing $\mathrm{Cu}$ content. This demonstrates that true alloying takes place for $\mathrm{Cu}$ - and $\mathrm{Fe}$-rich powders, respectively. This has also been confirmed by TEM and Mössbauer spectrometry. ${ }^{21}$ The increase of the bcc NND with increasing $\mathrm{Cu}$ content can be explained by the increasing fraction of larger $\mathrm{Cu}$ atoms. The NND of the bcc phase roughly follows Vegard's law (dashed line in Fig. 1) given the error bars for our data. The expansion of the fcc NND with increasing amount of smaller $\mathrm{Fe}$ atoms is attributed to elastic strain and magnetovolume effects. ${ }^{17}$ Due to the latter 


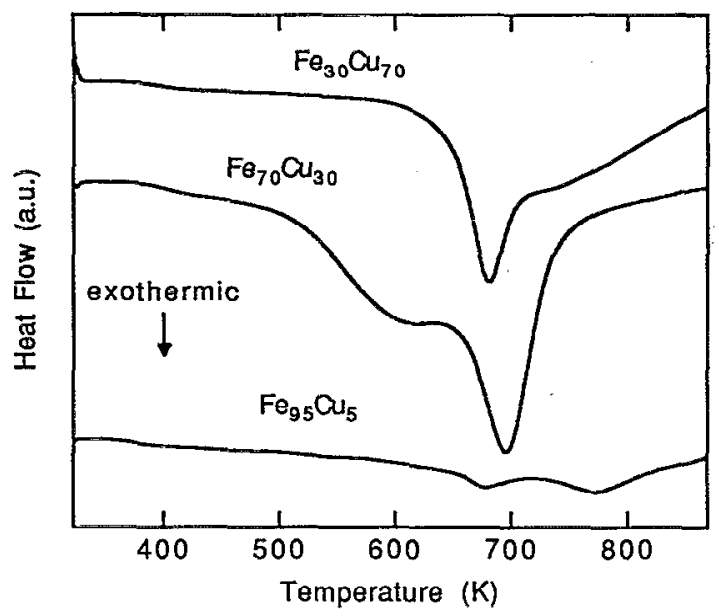

FIG. 2. Typical DSC scans for $\mathrm{Fe}_{x} \mathrm{Cu}_{100-x}$ alloys after $24 \mathrm{~h}$ of milling at a heating rate of $20 \mathrm{~K} / \mathrm{min}$.

effects the compositional dependence of the NND for fcc alloys cannot be described by Vegard's law. In the twophase region from 60 to 80 at. \% Fe the NND of the fcc phase decreases as a function of overall $\mathrm{Fe}$ content. The data suggest that the $\mathrm{Fe}$ content of the fcc phase drops from about 30 at. $\% \mathrm{Fe}$ for $\mathrm{Fe}_{60} \mathrm{Cu}_{40}$ to zero for $x>75$. On the other hand, the NND of the bec phase remains constant in the two-phase region with increasing overall $\mathrm{Cu}$ content, indicating that -20 at. $\% \mathrm{Cu}$ is dissolved in the bcc phase. This compositional dependence of the NND in the two-phase region is in apparent contrast to what one would expect for a metastable thermodynamic equilibrium between the fcc and bcc solid solutions. In this case, two phases with fixed composition and compositionindependent NND's would coexist, and only the relative amounts of both phases would vary with the overall composition. The observed compositional dependence of the fcc NND indicates that the phase formation during mechanical alloying is governed by the kinetics of milling rather than by the thermodynamic conditions of the material. Our measured nearest-neighbor distances are consistent with the data reported for other mechanically alloyed powders, ${ }^{16,17}$ samples obtained by liquid quenching, ${ }^{13}$ and evaporated alloys ${ }^{11-13}$ (for details see Refs. 7 and 9).

The thermal stability of the powders was investigated by DSC. Figure 2 shows the DSC traces for $\mathrm{Fe}_{30} \mathrm{Cu}_{70}$, $\mathrm{Fe}_{70} \mathrm{Cu}_{30}$, and $\mathrm{Fe}_{95} \mathrm{Cu}_{5}$ after $24 \mathrm{~h}$ of milling as typical examples. The DSC scans exlibit two exothermic peaks for all samples. For single-phase fcc $(x<60)$ and bec alloys $(x>80)$ the first exotherm is sharper than the second peak which appears only as a broad shoulder for the fcc alloys. On the other hand, samples in the two-phase region exhibit a rather broad and weak first exotherm and a sharper hightemperature peak.

To get more insight into the nature of the two exothermic events we performed annealing experiments for powders with different compositions. For this, we heated samples at $20 \mathrm{~K} / \mathrm{min}$ in the DSC to the onset of the first exotherm, between the two exotherms and to $870 \mathrm{~K}$. After heating to these temperatures the samples were rapidly cooled in the DSC and investigated at room temperature by $x$-ray diffraction. As typical examples. Figs. 3(a)-3(c) show x-ray-diffraction patterns for $\mathrm{Fe}_{30} \mathrm{Cu}_{70}, \mathrm{Fe}_{70} \mathrm{Cu}_{30}$, and $\mathrm{Fe}_{95} \mathrm{Cu}_{5}$ after $24 \mathrm{~h}$ of milling and after heating to different temperatures. Single-phase fcc powder heated to the onset of the low-temperature exotherm ( $590 \mathrm{~K}$ for $\mathrm{Fe}_{30} \mathrm{Cu}_{70}$ ) shows no significant change of the diffraction pattern [Fig. 3 (a)]. In particular, no bcc Fe lines are visible. The decrease of the FWHM of the x-ray peaks indicates that a small amount of strain release and/or grain growth occurs during this step. Heating this powder to $710 \mathrm{~K}$ results in phase separation, clearly indicated by the presence of bcc lines in the X-ray-diffraction pattern [Fig. 3(a)]. During heating to $870 \mathrm{~K}$ further recovery occurs, indicated by the sharpening of the diffraction peaks. Similar results were obtained for all the fcc samples investigated.

The results obtained for heating samples with twophase microstructure to different temperatures are presented in Fig. 3(b) for $\mathrm{Fe}_{70} \mathrm{Cu}_{30}$ as a typical example. Heating to the onset of the low-temperature exotherm leads to a slight sharpening of the fcc and bcc Bragg peaks, indicating that a small amount of recovery occurs even before the first exotherm. Heating to $635 \mathrm{~K}$-the local minimum between the two DSC exotherms-leads to a significant sharpening of the bcc Bragg peaks. Heating to $870 \mathrm{~K}$ results in chemical redistribution, grain growth, and structural relaxation for both fec and bcc phases.

The x-ray-diffraction peaks of single-phase bcc alloys also sharpen during heating to elevated temperatures, indicating that strain release and grain growth occur in these samples [Fig. 3(c)]. Heating to $570 \mathrm{~K}$ leads to a small amount of recovery. At $720 \mathrm{~K}$-above the first exotherma significant amount of recovery has occurred for the bcc phase, and there is evidence of the (111) peak of the fcc phase at $2 \Theta \approx 49^{\circ}$. Heating to $870 \mathrm{~K}$ results in further phase separation and grain growth. The additional Bragg peaks of the annealed sample can be indexed to $\mathrm{Fe}_{3} \mathrm{O}_{4}$.

A detailed comparison of the changes in average grain size, rms atomic-level strain, and nearest-neighbor distance upon annealing is shown in Figs. 4-6 for single-phase fcc $\mathrm{Fe}_{30} \mathrm{Cu}_{70}$, the two-phase mixture $\mathrm{Fe}_{70} \mathrm{Cu}_{30}$, and singlephase bcc $\mathrm{Fe}_{95} \mathrm{Cu}_{5}$ as typical examples. In the case of single-phase fcc alloys a small amount of grain growth from $\sim 13$ to $\sim 14 \mathrm{~nm}$ and strain release from $0.33 \%$ to $0.23 \%$ occur during heating to the onset of the first exotherm [Figs. 4(a) and 5(a)]. The fcc NND remains nearly unchanged during this step [Fig. 6(a)], indicating that no change in composition and, therefore, no pronounced phase separation occurs. Heating above the first exotherm leads to formation of the bcc phase but with very little grain growth of the fcc phase: The fcc grain size increases from $\sim 14$ to $\sim 18 \mathrm{~nm}$ [Fig. 4(a)]. The rms strain at this stage is virtually the same as for the powder heated to 590 $\mathrm{K}$ [Fig. 5(a)]. The phase separation is evidenced by the decrease in the fcc NND [Fig. 6(a)]. The data indicate that the Fe content of the fcc phase drops from 20 at. \% for the as-milled powder to about 13 at. \%, as determined from comparison with the NND of single-phase as-milled 

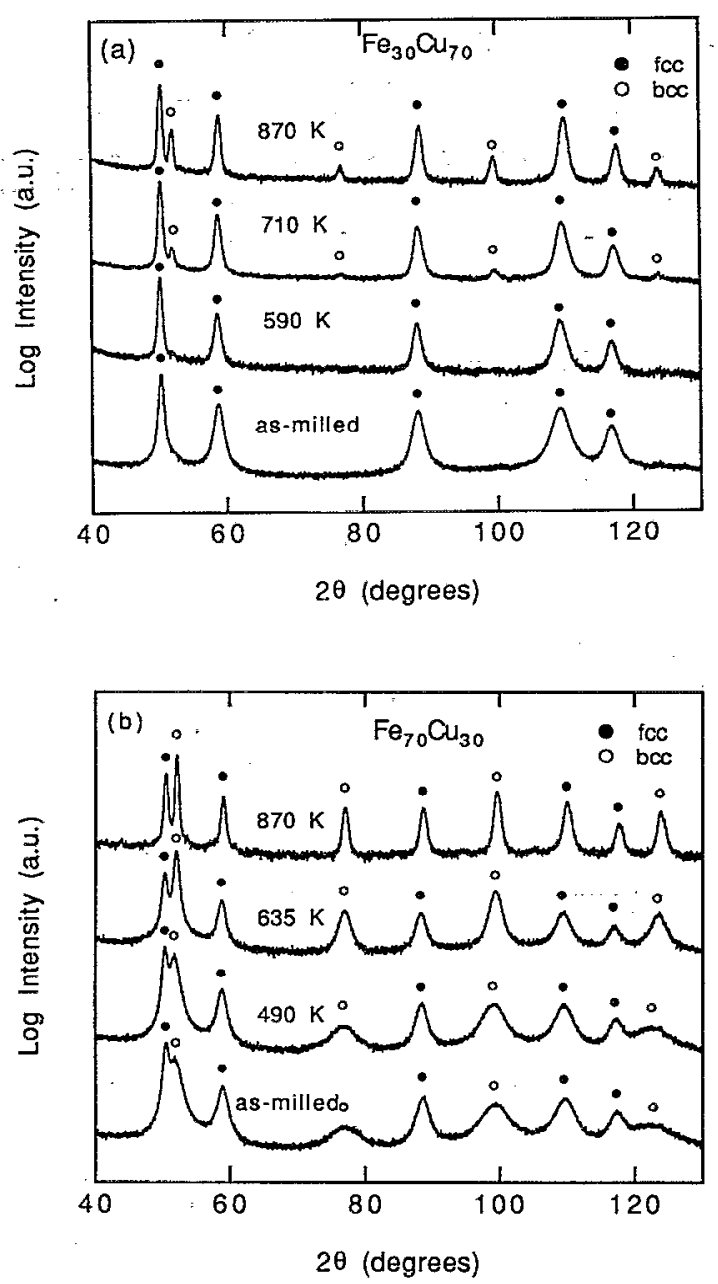

fcc powders. Upon heating to $870 \mathrm{~K}$, the fcc NND drops to the value for pure $\mathrm{Cu}$, leading to elimination of the atomiclevel strain, but very little further grain growth of the fcc phase occurs $(d \sim 19 \mathrm{~nm})$. On the other hand, the grain size of the bcc phase increases from $\sim 17$ to $\sim 22 \mathrm{~nm}$ during this step. The material is strain free and the nearestneighbor distance is essentially that of pure $\mathrm{Fe}$.

Similar to the single-phase fcc alloys, the fcc grain size for samples in the two-phase region increases only slightly from $\sim 8$ to $\sim 10 \mathrm{~nm}$ upon heating to the onset of the first exotherm [Fig. 4(b)]. However, the strain does not decrease as in the case of single-phase fcc alloys, but remains nearly constant during heating to $490 \mathrm{~K}$ [Fig. 5(b)]. Heating above the first exotherm leads to strain release, and heating to $870 \mathrm{~K}$ results in a strain-free fcc phase. Simultaneously, the fec grain size continuously increases to $\sim 13$ $\mathrm{nm}$ at $635 \mathrm{~K}$ and $\sim 22 \mathrm{~nm}$ after heating to $870 \mathrm{~K}$. This is in contrast to the saturation of the fcc grain size of singlephase fcc alloys for $>710 \mathrm{~K}$. However, the final grain sizes at $870 \mathrm{~K}$ are comparable: $19 \mathrm{~nm}$ for the fec phase is initially single-phase fcc powder and $22 \mathrm{~nm}$ for the two-phase mixture. The grain size of the bcc phase in $\mathrm{Fe}_{70} \mathrm{Cu}_{30}$ increases rapidly above $490 \mathrm{~K}$ from $\sim 3$ to $\sim 24 \mathrm{~nm}$ after heating to $870 \mathrm{~K}$. Simultaneously, the rms strain drastically decreases from $\sim 1.5 \%$ to essentially zero [Fig. $5(\mathrm{~b})$ ]. Thus, the grain growth and the strain release of the bcc

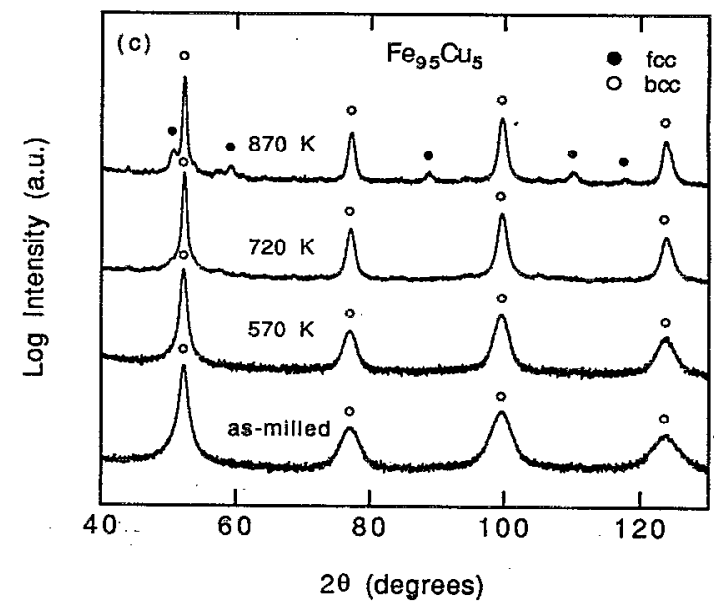

FIG. 3. X-ray-diffraction patterns (Co $K \alpha$ radiation) for (a) $\mathrm{Fe}_{30} \mathrm{Cu}_{70}$, (b) $\mathrm{Fe}_{70} \mathrm{Cu}_{30}$, and (c) $\mathrm{Fe}_{95} \mathrm{Cu}_{5}$ after milling for $24 \mathrm{~h}$ and subsequent heating at $20 \mathrm{~K} / \mathrm{min}$ in the DSC to diffcrent temperatures. After heating to the indicated temperatures the samples were quickly cooled to room temperature for $\mathrm{X}$-ray analysis.

phase in the two-phase mixture is even more pronounced than for the fcc phase [Figs. 4(b) and 5(b)]. Another difference from single-phase fcc alloys is the temperature dependence of the nearest-neighbor distance [Fig. 6(b)]. In contrast to homogeneous fcc alloys, the fcc NND already decreases during heating to $490 \mathrm{~K}$-the temperature below the onset of the low-temperature exotherm-and reaches the value for pure $\mathrm{Cu}$ after heating to $635 \mathrm{~K}$. This indicates that chemical redistribution of the fcc phase in two-phase mixtures occurs at lower temperatures than for initially single-phase fcc alloys. It is interesting to note that the fcc phase in $\mathrm{Fe}_{70} \mathrm{Cu}_{30}$ seems to become depleted in $\mathrm{Fe}$ faster than the bcc phase depletes in Cu: The fcc NND decreases significantly upon heating to $490 \mathrm{~K}$, whereas the bcc NND remains nearly constant. Heating to $635 \mathrm{~K}$ results in essentially pure $\mathrm{Cu}$, but the NND data show that $\sim 11$ at. $\%$ $\mathrm{Cu}$ remain dissolved in the bcc phase at this temperature [Fig. 6(b)]. Heating to $870 \mathrm{~K}$ is nccessary to expel all $\mathrm{Cu}$ atoms from the bcc lattice. This is in contrast to what has been observed for sputtered fec/bcc Fe-Cu two-phase mixtures annealed at $570 \mathrm{~K},{ }^{22}$ where the bcc phase depletes in $\mathrm{Cu}$ but the fcc phase does not deplete in $\mathrm{Fe}$. Our results indicate that two-phase mixtures coarsen and phase separate much easier than homogeneous fcc alloys, suggesting that grains of a second-phase enhance phase separation and grain growth by eliminating the need to nucleate this sec- 

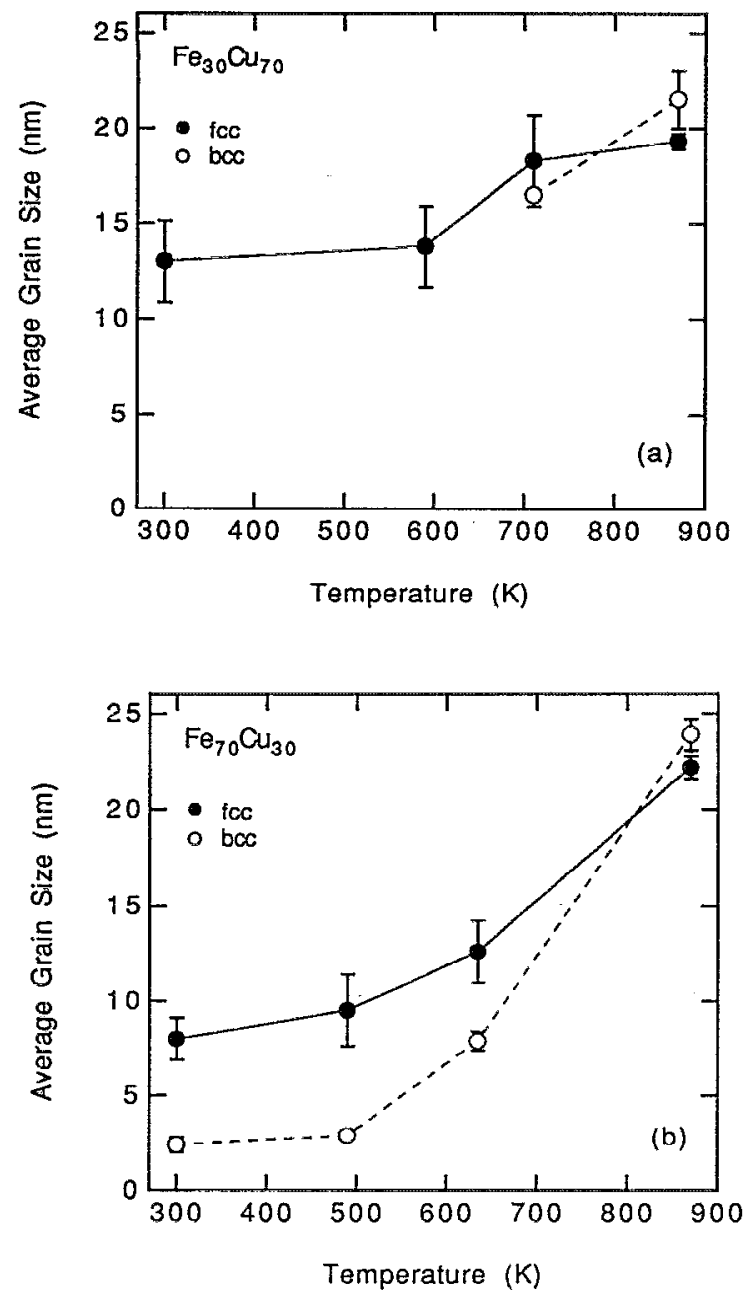

ond phase. This lowers the stability of structurally inhomogeneous powders.

The recovery behavior of single-phase bcc alloys is shown in Figs. 4(c), 5(c), and 6(c) for $\mathrm{Fe}_{95} \mathrm{Cu}_{5}$ as a typical example. Heating to $570 \mathrm{~K}$ slightly increases the bcc grain size from about $5 \mathrm{~nm}$ for the as-milled powder to about $7 \mathrm{~nm}$ [Fig. 4(c)]. Simultaneously, the strain drops from $0.62 \%$ to $0.4 \%$ [Fig. $5(\mathrm{c})$ ]. The nearest-neighbor distance remains unchanged during this step [Fig. 6(c)], indicating that no pronounced phase separation occurs. During heating to $720 \mathrm{~K}$ the grains grow to about $15 \mathrm{~nm}$ and the strain drops to $0.16 \%$. At this temperature, a small amount of fcc phase has formed, as indicated by the (111) Bragg line at $2 \theta \approx 49^{\circ}$ [Fig. 3(c)]. This phase separation is evidenced by the decreases in the bcc NND [Fig. 6(c)]. Heating to $870 \mathrm{~K}$ leads to further phase separation, grain growth to about $21 \mathrm{~nm}$ for the bcc phase, and strain release to less than $0.1 \%$. The grain size of the fcc phase is $\sim 14$ $\mathrm{nm}$ at $870 \mathrm{~K}$. Thus, the grain growth behavior of homogeneous bcc alloys is somewhat different than that of single-phase fcc alloys. Very little grain growth occurs until an fcc phase forms. Once the fcc phase forms, the bec grains coarsen significantly without saturation as observed for the fcc grains in initially single-phase fcc $\mathrm{Fe}_{30} \mathrm{Cu}_{70}$. Furthermore, the rms strain of the bcc phase drops significantly during heating to $720 \mathrm{~K}$, whereas the strain of the

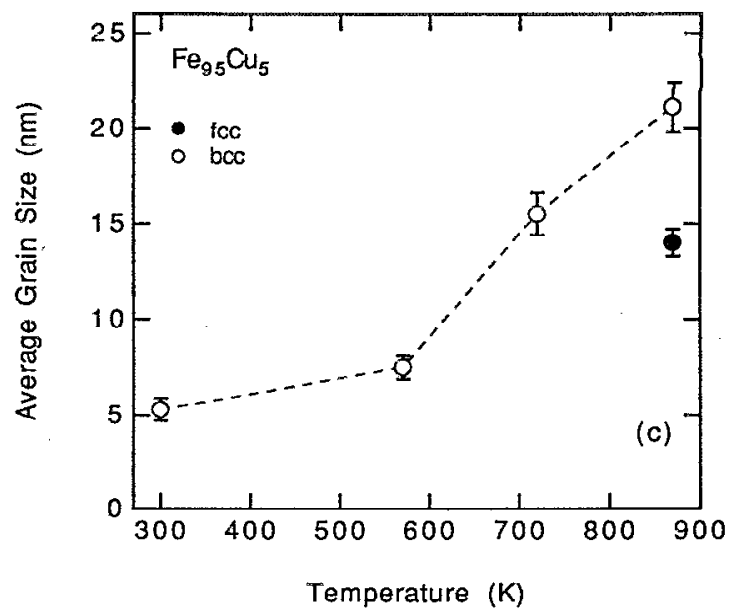

FIG. 4. Average grain size for (a) $\mathrm{Fe}_{30} \mathrm{Cu}_{70}$, (b) . $\mathrm{Fe}_{70} \mathrm{Cu}_{30}$, and (c) $\mathrm{Fe}_{95} \mathrm{Cu}_{5}$ powders as a function of annealing temperature $[(\bullet)$ fcc phase and $(O)$ bcc phase]. The samples were heated at $20 \mathrm{~K} / \mathrm{min}$ in the DSC to the indicated temperature, and quickly cooled to room temperature for $\mathrm{x}$-ray analysis.

fcc phase in $\mathrm{Fe}_{30} \mathrm{Cu}_{70}$ decreases only slightly up to this temperature. The final bcc grain size of $21 \mathrm{~nm}$ after heating to $870 \mathrm{~K}$ is nearly the same as for the bcc material formed during phase separation of $\mathrm{Fe}_{30} \mathrm{Cu}_{70}(d \sim 22 \mathrm{~nm})$ and for the bcc phase in $\mathrm{Fe}_{70} \mathrm{Cu}_{30}(d \sim 24 \mathrm{~nm})$. On the other hand, the fcc grain size in $\mathrm{Fe}_{95} \mathrm{Cu}_{5}$ after heating to $870 \mathrm{~K}$ is $\sim 14$ $\mathrm{nm}$, which is smaller than the fcc grain sizes for initially single-phase $\mathrm{Fe}_{30} \mathrm{Cu}_{70}(d \sim 19 \mathrm{~nm})$ and the $\mathrm{Fe}_{70} \mathrm{Cu}_{30}$ twophase mixture $(d \sim 24 \mathrm{~nm})$ at the same temperature. Furthermore, after heating to $870 \mathrm{~K}$ the fcc NND in $\mathrm{Fe}_{95} \mathrm{Cu}_{5}$ of $0.2564 \mathrm{~nm}$ is larger than that of the fcc phase in the $\mathrm{Fe}_{30} \mathrm{Cu}_{70}$ and $\mathrm{Fe}_{70} \mathrm{Cu}_{30}$ powders at the same temperature: The measured NND indicates that $\sim 10$ at. \% Fe remain dissolved in the fcc phase.

The peak temperatures of the DSC exotherms, $T_{1}$ and $T_{2}$, as well as the partial enthalpy release associated with each peak, $\Delta H_{1}$ and $\Delta H_{2}$, vary with composition. For single-phase fcc alloys the first maximum increases continuously with increasing Fe content and remains nearly constant for more than 30 at. \% Fe (Fig. 7). Even small additions of $\mathrm{Fe}$ (e.g., 10 at. $\%$ ) increase $T_{1}$ by about $100 \mathrm{~K}$ above the exothermic peak observed for pure $\mathrm{Cu}$ at $\sim 530$ $\mathrm{K}$, which has been shown to be due to grain growth. ${ }^{6} \mathrm{On}$ the other hand, $T_{1}$ of single-phase bec alloys seems to be independent of composition. The measured $T_{1}$ values in this regime are comparable to the data obtained for single- 

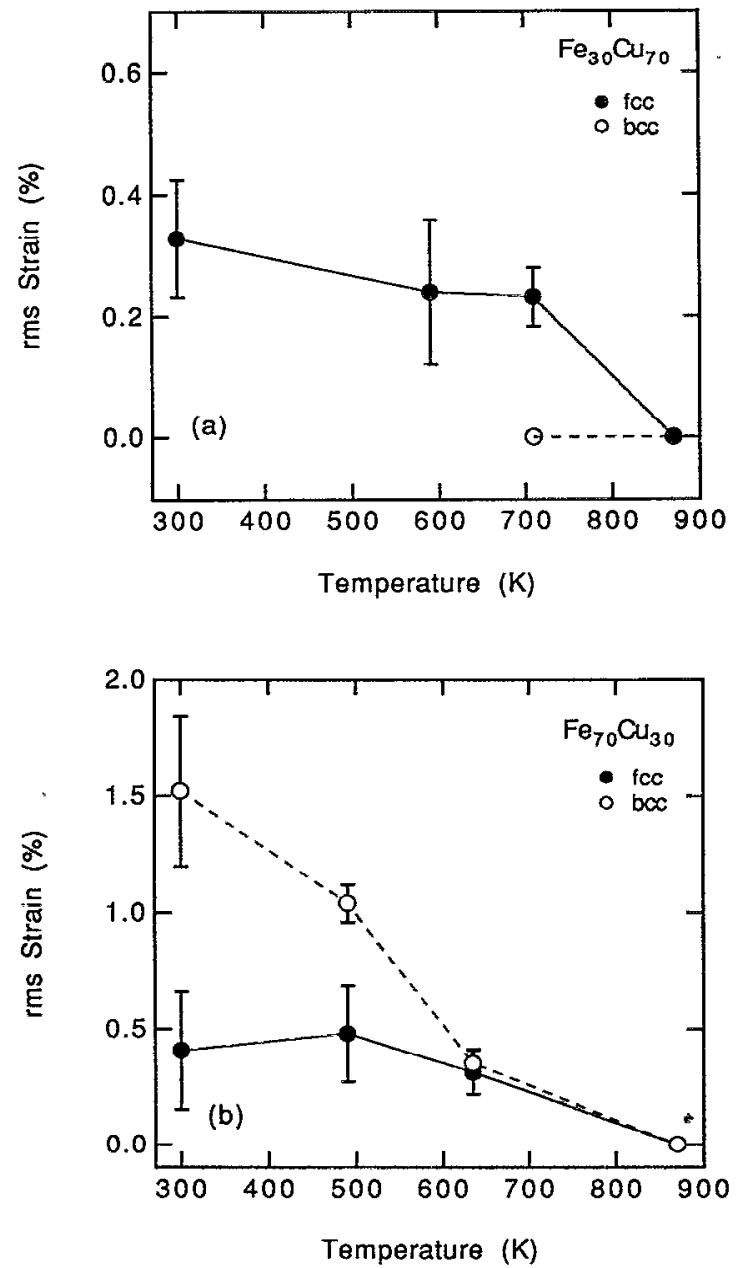

phase fcc alloys with $x>30$. The peak temperature of the first exothermic event for single-phase alloys with more than 30 at. $\% \mathrm{Fe}(\sim 670 \mathrm{~K})$ is in good agreement with the pronounced grain growth peak at $665 \mathrm{~K}$ observed for ballmilled pure $\mathrm{Fe}^{23}$ These results suggest that additions of $\mathrm{Fe}$ in homogeneous fcc alloys improve their stability compared to pure nanocrystalline $\mathrm{Cu}$, whereas additions of $\mathrm{Cu}$ in bcc alloys do not significantly affect the stability of these alloys. In contrast, samples in the two-phase region exhibit significantly reduced $T_{1}$ values, indicated that these samples are less than homogeneous solid solutions.

The maximum of the second exothermic peak $T_{2}$ is in general about $50 \mathrm{~K}$ larger than $T_{1}$ for all samples (Fig. 7). For single-phase fcc alloys $T_{2}$ is nearly independent of composition. For single-phase bcc alloys $T_{2}$ decreases with increasing $\mathrm{Cu}$ content from about $770 \mathrm{~K}$ for $\mathrm{Fe}_{95} \mathrm{Cu}_{5}$ to about $720 \mathrm{~K}$ for $\mathrm{Fe}_{85} \mathrm{Cu}_{15}$, which is comparable to the $T_{2}$ values of single-phase fec alloys. Howcver, in the twophase region the peak temperature of the second exotherm decreases with increasing $\mathrm{Fe}$ content to a value which is comparable to the maximum of the first exotherm of homogeneous samples.

Figure 8 shows the composition dependence of the partial enthalpy release, $\Delta H_{1}$ and $\Delta H_{2}$, associated with the two exothermic DSC peaks. Unfortunately, the two exothermic events overlap for some samples. In these cases, we

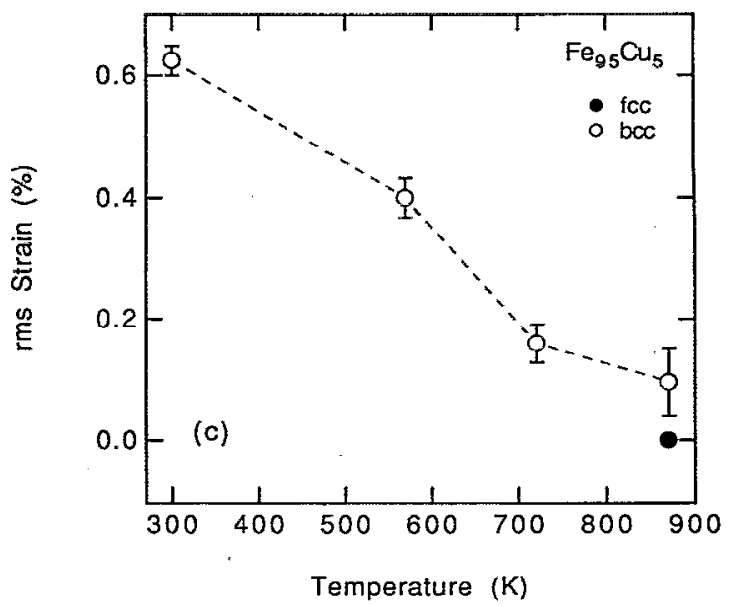

FIG. 5. Atomic-level strain for (a) $\mathrm{Fe}_{30} \mathrm{Cu}_{70}$, (b) $\mathrm{Fe}_{70} \mathrm{Cu}_{30}$, and (c) $\mathrm{Fe}_{95} \mathrm{Cu}_{5}$ powders as a function of annealing temperature $[(-)$ fcc phase and $(O)$ bcc phase]. The samples were heated at $20 \mathrm{~K} / \mathrm{min}$ in the DSC to the indicated temperature, and quickly cooled to room temperature for $\mathrm{x}$-ray analysis.

fit the DSC curves to two distinct exothermic peaks to obtain an estimate for $\Delta H_{1}$ and $\Delta H_{2}$. For single-phase fcc alloys the enthalpy release during the first exothermic reaction increases from about $0.5 \mathrm{~kJ} / \mathrm{mol}$ for $\mathrm{Fe}_{10} \mathrm{Cu}_{90}$ to about $2.3 \mathrm{~kJ} / \mathrm{mol}$ for $\mathrm{Fe}_{40} \mathrm{Cu}_{60}$. For $40<x<60 \Delta H_{1}$ decreases again. The measured values are much larger than the enthalpy release for homogeneous bcc alloys $\left(\Delta H_{1} \sim 0.3 \mathrm{~kJ} / \mathrm{mol}\right.$ ), which is independent of composition. For samples in the two-phase region the $\Delta H_{1}$ values of $0.4-0.6 \mathrm{~kJ} / \mathrm{mol}$ - which refer to the weaker DSC peakare much smaller than for homogeneous fcc alloys and comparable to the $\Delta H_{2}$ values of the second exotherm of these alloys $\left(\Delta H_{2}=0.3-0.6 \mathrm{~kJ} / \mathrm{mol}\right)$. On the other hand, the stronger second exotherm is associated with a large enthalpy release, similar to the first exotherm of singlephase fcc alloys.

The enthalpy release associated with the second exotherm in fcc alloys, and the first peak in two-phase mixtures and single-phase bcc alloys, is comparable to the enthalpy release upon grain growth of ball-milled elemental $\mathrm{Fe}(\Delta H=0.16 \mathrm{~kJ} / \mathrm{mol}) .{ }^{23}$ In contrast, the enthalpies of the first exotherm in fcc alloys and the second exotherm in two-phase samples are much larger than these values (Fig. 8 ). This indicates that the DSC peaks with the small heat release are related to grain growth, whereas the peaks with large $\Delta H$ include a larger amount of heat release associated 

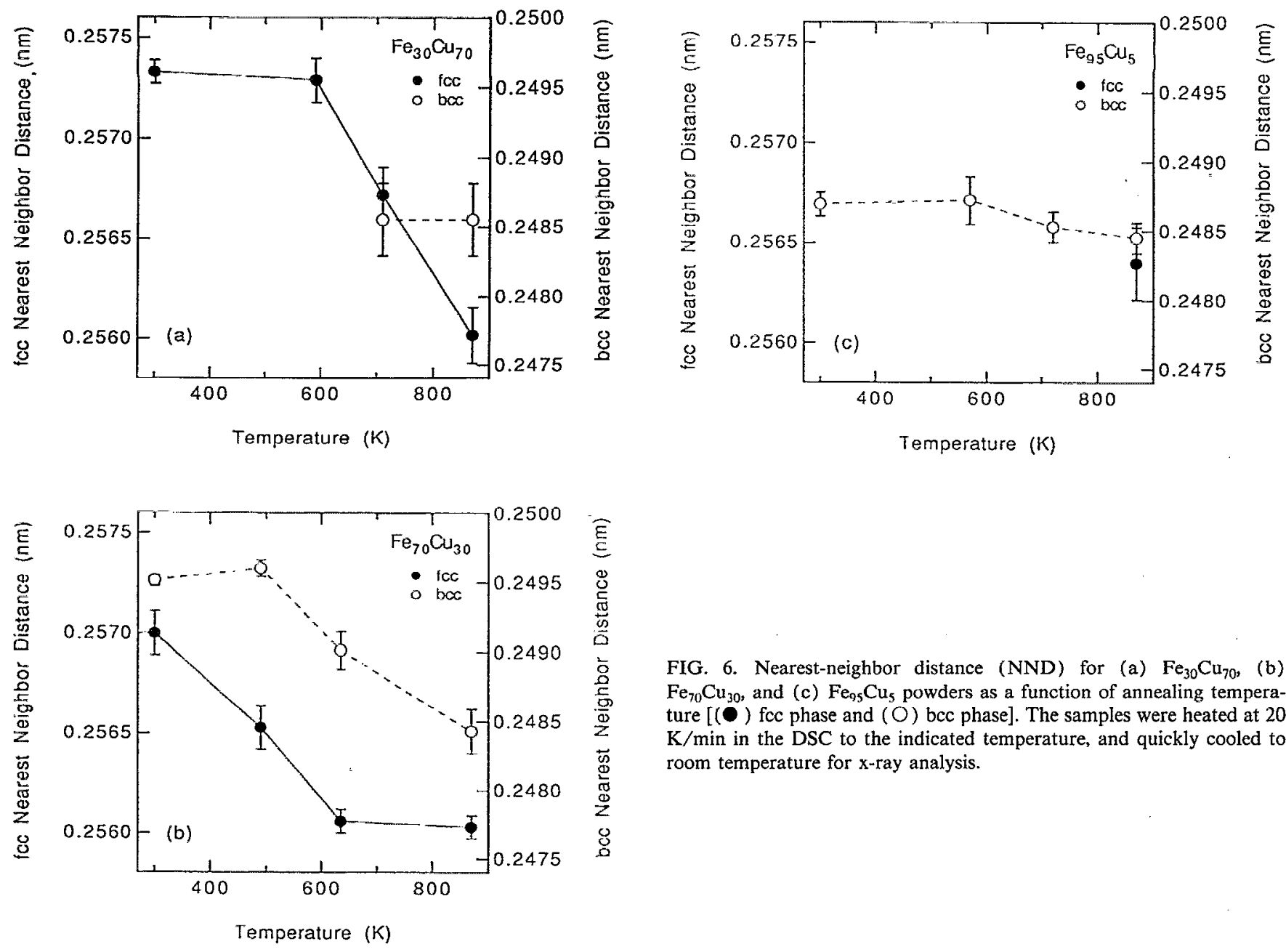

FIG. 6. Nearest-neighbor distance (NND) for (a) $\mathrm{Fe}_{30} \mathrm{Cu}_{70}$, (b) $\mathrm{Fe}_{70} \mathrm{Cu}_{30}$, and (c) $\mathrm{Fe}_{95} \mathrm{Cu}_{5}$ powders as a function of annealing temperature $[(-)$ fcc phase and $(O)$ bcc phase]. The samples were heated at 20 $\mathrm{K} / \mathrm{min}$ in the DSC to the indicated temperature, and quickly cooled to room temperature for $\mathrm{x}$-ray analysis.

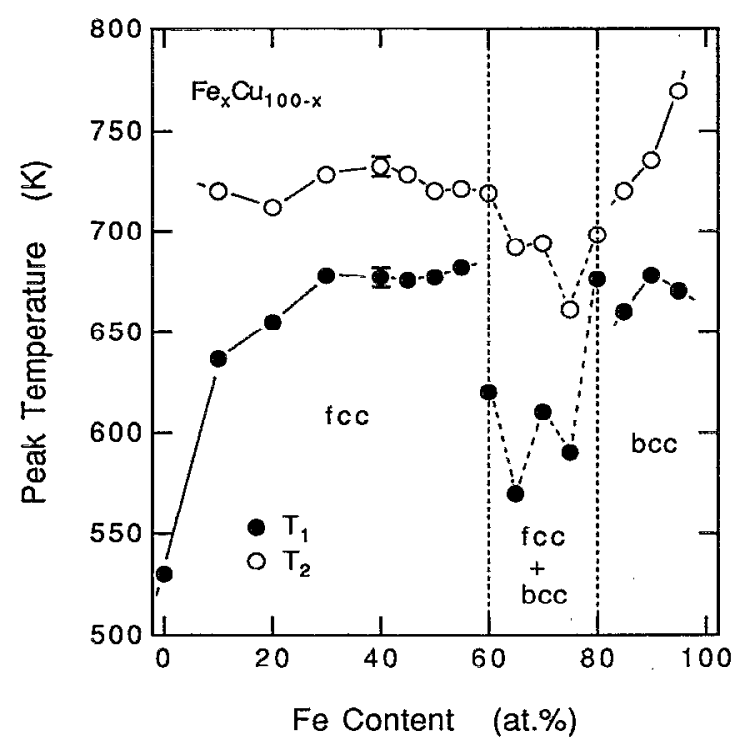

FIG. 7. Compositional dependence of the peak temperature for the first (O) and the second (O) exothermic maximum in the DSC scans (heating rate $20 \mathrm{~K} / \mathrm{min}$ ) for $\mathrm{Fe}_{x} \mathrm{Cu}_{100-x}$ powders after $24 \mathrm{~h}$ of milling.

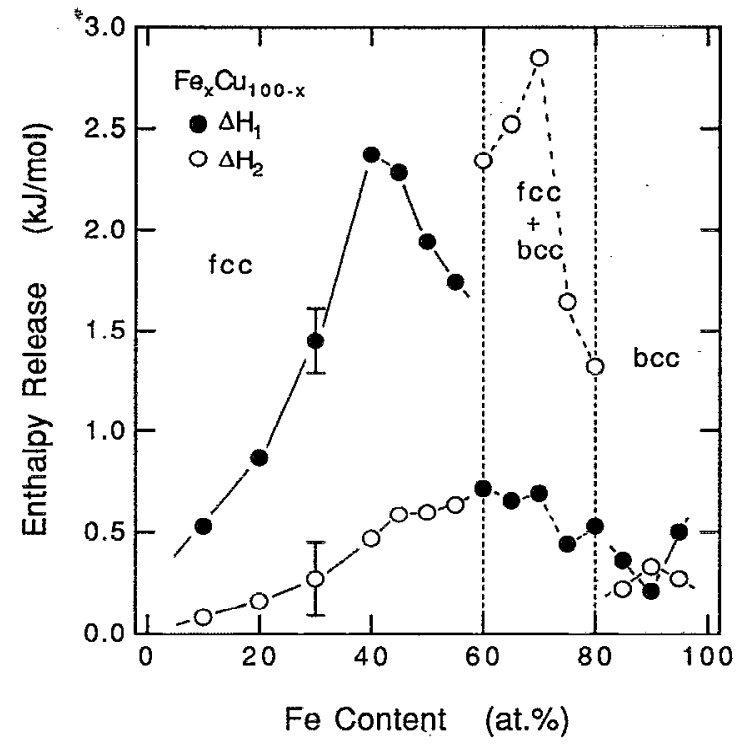

FIG. 8. Compositional dependence of the enthalpy release associated with the first (O) and the second (O) exothermic peak in the DSC scans for $\mathrm{Fe}_{x} \mathrm{Cu}_{100-x}$ powders after $24 \mathrm{~h}$ of milling. 
TABLE II. Activation energies for different mechanisms of $\mathrm{Fe}$ and $\mathrm{Cu}$ diffusion. The data are taken from Ref. 25.

\begin{tabular}{lc}
\hline \hline Mechanism & Activation energy (eV) \\
\hline$\alpha$-Fe self-diffusion & 2.6 \\
$\gamma$-Fe self-diffusion & 3.0 \\
Fe grain-boundary diffusion & 1.7 \\
Fe diffusion in Cu & 2.2 \\
Cu self-diffusion & 2.1 \\
Cu grain-boundary diffusion & 1.3 \\
Cu diffusion in Fe & 2.9 \\
\hline
\end{tabular}

with chemical effects, i.e., phase separation. A strong exothermic peak precedes a rather small second exotherm for single-phase fcc alloys, indicated that phase separation precedes and/or initiates grain growth in these samples. In contrast, a small exotherm precedes a much larger exothermic peak for the two-phase mixtures. The changes in grain size and nearest-neighbor distance [Figs. 4(b) and 6(b)] indicate that the fcc and bcc grains in these powders start to coarsen during this peak and that strong chemical redistribution occurs, especially for the fcc phase. No clear statement can be made from the $T_{1,2}$ and $\Delta H_{1,2}$ values of the bcc alloys, since both exotherms are associated with comparable heat releases (Fig. 8).

To obtain data on the kinetics of phase separation and grain growth we studied the shift in peak temperatures upon changes in heating rate for the sharp exothermic first peaks for single-phase fcc and bcc alloys, and the sharp second exothermic DSC peaks for two-phase mixtures with a Kissinger analysis ${ }^{24}$ (no reliable data could be obtained for the broad DSC peaks). Since presumably both phase separation and grain growth occur simultaneously as shown above, the validity of a Kissinger analysis in terms of a single process is not strictly fulfilled. Thus, the determination of activation energies for these peaks can only give a qualitative hint for the underlying processes occurring during the exothermic events. The measured activation energies are nearly independent of composition for alloys with the same lattice: $2.1 \pm 0.1 \mathrm{eV}$ for the singlephase fcc alloys and $2.7 \pm 0.1 \mathrm{eV}$ for the single-phase bcc alloys. The activation energy for the sharp DSC peak for two-phase mixturcs is $2.0 \pm 0.1 \mathrm{eV}$. The literature data for the activation energies for $\mathrm{Fe}$ and $\mathrm{Cu}$ diffusion are given in Table II. The comparison of our measured data with the literature values shows that the activation energies for the sharp DSC peaks for fcc alloys of $2.1 \pm 0.1$ and $2.0 \pm 0.1 \mathrm{eV}$ for the two-phase alloys are nearly identical to the value for $\mathrm{Cu}$ self-diffusion, i.e., $\mathrm{Cu}$ grain-boundary migration, and $\mathrm{Fe}$ diffusion in $\mathrm{Cu}$, suggesting that both phase separation and grain growth occur simultaneously. This is consistent with the finding that $\Delta H_{1}$ for the fcc alloys and $\Delta H_{2}$ for the two-phase alloys are much larger than a value which is characteristic solely for grain growth, but likely contains a chemical contribution due to phase separation, as shown above. For bcc alloys the measured activation energy of $2.7 \pm 0.1 \mathrm{eV}$ is nearly identical to the value for $\mathrm{Fe}$ self-diffusion, i.e., $\mathrm{Fe}$ grain-boundary migration, and only slightly smaller than the value of $2.9 \mathrm{eV}$ for $\mathrm{Cu}$ diffusion in $\mathrm{Fe}$. This indicates that both phase separation and grain growth also occur simultaneously for bcc alloys.

The nature of the second DSC exotherm for singlephase bcc alloys is not yet clear (Fig. 2). Significant grain growth occurs even before the onset of this exotherm at $720 \mathrm{~K}$ [Fig. 4(c)]. In addition, the nearest-neighbor distance of the material decreases during heating to $720 \mathrm{~K}$ [Fig. 6(c)]. This indicates that significant grain growth and decomposition of the bcc $\mathrm{Fe}-\mathrm{Cu}$ solid solution already occurred during the first DSC peak. However, the fcc phase contains about 10 at. \%. Fe even after heating to $870 \mathrm{~K}$ [Fig. 6(c)]. The activation energy for the second DSC exotherm of this powder is $2.2 \pm 0.1 \mathrm{eV}$, which is comparable to the activation energy for $\mathrm{Cu}$ self-diffusion and for $\mathrm{Fe}$ diffusion in $\mathrm{Cu}$. Upon heating above the first exotherm some $\mathrm{Cu}$ atoms might be expelled to grain boundaries and/ or form very small $\mathrm{Cu}$ particles with rather high $\mathrm{Fe}$ content. During the second exotherm these particles might grow and deplete in $\mathrm{Fe}$, which would explain why the measured activation energy has a value that is characteristic for $\mathrm{Cu}$ self-diffusion, i.e., $\mathrm{Cu}$ grain-boundary migration, and for $\mathrm{Fe}$ diffusion in $\mathrm{Cu}$.

\section{DISCUSSION}

The nanocrystalline $\mathrm{Fe}_{x} \mathrm{Cu}_{100-x}$ solid solutions phase separate and coarsen upon heating to elevated temperatures. The temperature range for pronounced phase separation and grain growth between 570 and $720 \mathrm{~K}$ for our single-phase fcc and bcc alloys agrees reasonably well with the temperature of $570 \mathrm{~K}$ previously reported for the onset of phase separation in sputtered polycrystalline $\mathrm{Fe}-\mathrm{Cu}$ solid solutions ${ }^{22}$ and with the temperatures of $>720 \mathrm{~K}$ for rapidly quenched fcc and bcc samples. ${ }^{26-31}$ The results obtaincd from the investigation of the maximum temperatures of the DSC peaks and the heat release associated with the peaks, as well as the detailed analysis of the changes in grain size, atomic-level strain, and the nearest-neighbor distance upon annealing indicate that the stability of the metastable nanocrystalline $\mathrm{Fe}$-Cu alloys is governed by the kinetics of phase separation and grain growth.

The first exotherm of the DSC traces is nearly independent of composition for all single-phase fec alloys with $x>30$ (Fig. 7). No significant grain growth occurs for these alloys before phase separation sets in [Figs. 4(a) and 4(c)]. This occurs around a temperature of about $670 \mathrm{~K}$ which is characteristic for the grain growth of ball-milled nanocrystalline $\mathrm{Fe}^{23}$ This temperature is significantly larger than the temperature for pronounced grain growth in elemental nanocrystalline $\mathrm{Cu}$ of about $530 \mathrm{~K}$ (Fig. 7). The increase in $T_{1}$ of Fe-rich fec alloys compared to pure $\mathrm{Cu}$ indicates that $\mathrm{Fe}$ additions enhance the stability of nanocrystalline fcc phase. This can be understood in terms of the cohesive energy of $\mathrm{Fe}$ and $\mathrm{Cu}$. Since in grain boundaries more bonds are broken than in the bulk of a grain, elements with lower cohesive energy tend to segregate to grain boundaries. In other words, such an element has a smaller grain-boundary energy. Since the cohesive energy of $\mathrm{Cu}(3.55 \mathrm{eV})$ is smaller than that of $\mathrm{Fe}(4.25 \mathrm{eV}),{ }^{32} \mathrm{Cu}$ 
atoms are more likely to concentrate on grain boundaries than $\mathrm{Fe}$ atoms. Thus, migration of $\mathrm{Fe}$ atoms to grain boundaries is unlikely. Since the activation energy for $\mathrm{Cu}$ self-diffusion (i.e., $\mathrm{Cu}$ grain-boundary migration) and the activation energy for $\mathrm{Fe}$ diffusion in $\mathrm{Cu}$ are comparable, demixing and redistribution effects might be comparable, and phase separation can only occur when the mobility of $\mathrm{Fe}$ atoms is high enough to nucleate $\mathrm{Fe}$ particles.

It has been shown that in the early stages, Fe precipitates as coherent fcc particles from supersaturated fcc Fe$\mathrm{Cu}$ alloys. ${ }^{22}$ These precipitates remain coherent up to a size of about $20 \mathrm{~nm}$ before transforming to the stable bcc $\alpha$-Fe phase. Since the nearest-neighbor distance of $\gamma$ - $\mathrm{Fe}$ at room temperature $(0.2516 \mathrm{~nm})$ (Ref. 29) is even smaller than that of pure $\mathrm{Cu}(0.2556)$ and the coherent precipitates would introduce elastic coherency strains in the material, ${ }^{27}$ one should be able to detect the formation of coherent $\mathrm{Fe}$ precipitates in the supersaturated fcc $\mathrm{Fe}$-Cu solid solutions; however, we found no evidence for the formation of any fcc $\mathrm{Fe}$ phase in our samples. Hence, we believe that in our fcc alloys phase separation is initiated by the nucleation of bcc $\mathrm{Fe}$. As long as $\mathrm{Fe}$ atoms are dissolved in the fcc lattice, these solute atoms might hinder the migration of $\mathrm{fcc} \mathrm{Cu}$ grain boundaries due to solute drag. ${ }^{33}$ Therefore, no pronounced grain growth of fcc alloys can be observed before the $\mathrm{Fe}$ atoms are removed from the solid solution, which occurs at a higher temperature than the temperature where grain growth occurs for pure nanocrystalline $\mathrm{Cu}$. This might explain the enhanced stability of nanocrystalline fcc $\mathrm{Fe}-\mathrm{Cu}$ solid solutions compared to pure nanocrystalline $\mathrm{Cu}$.

For samples in the two-phase region grain growth occurs at a much lower temperature, indicating that these chemically and structurally inhomogeneous samples are less stable than single-phase alloys. Our results show that coarsening, strain release, and phase separation occur during the first DSC exotherm [Figs. 4(b), 5(b), and 6(b)]. In particular, the fcc phase expels all Fe during this step. This suggests that grains of a second phase-fcc or bcc, respectively-enhance phase separation and grain growth by eliminating the need to nucleate the second phase. This agrees well with the finding that initial phase separation is necessary for the grain growth in homogeneous fcc alloys whereas samples in the two-phase region coarsen and phase separate readily even at quite low temperatures. Thus, chemical and structural homogeneity seems to be crucial for the stability of nanocrystalline materials.

For homogeneous bce alloys no grain growth and phase separation occur until the onset of the first DSC exotherm, similar to what has been observed for singlephase fcc alloys. The maximum temperature of this peak is consistent with the maximum temperature of the grain growth exotherm for pure $\mathrm{Fe}^{23} \mathrm{In}$ addition, the measured activation energy for this peak agrees well with the activation energy for Fe self-diffusion (i.c., Fc grain-boundary migration) and the activation energy for $\mathrm{Cu}$ diffusion in bcc Fe. This indicates that the stability of the bcc Fe-Cu solid solutions is not reduced by the presence of $\mathrm{Cu}$ atoms as one might suspect. This also confirms that the supersat- urated alloys exhibit a homogeneous bcc structure for $x$ $>80$. In the case of preexisting small $\mathrm{Cu}$ particles only further growth of these pre-existing grains would be required. Thus, phase separation would be governed by the self-diffusion of $\mathrm{Cu}$ atoms which can occur at much lower temperatures due to its smaller activation energy. This would give rise to a low-temperature exothermic DSC peak which was not observed in our DSC experiments.

In general, there are two possible sites for $\mathrm{Cu}$ atoms leaving the metastable bcc solid solution: (i) $\mathrm{Cu}$ atoms might form small clusters/precipitates within a grain or (ii) $\mathrm{Cu}$ atoms could segregate to grain boundaries of bcc crystallites. It has been shown that the $\mathrm{Cu}$ clusters that form in the early stages of precipitation from supersaturated bec solid solutions arc coherent as long as their diameter is smaller than about $5 \mathrm{~nm} .{ }^{22,25-28}$ Furthermore, the activation energy for the formation of these nuclei has been shown to be composition dependent with a broad minimum of about $0.6 \mathrm{eV}$ for nucleus compositions between 60 and 80 at. $\% \mathrm{Cu}^{26}$ Experimentally it was found that most of the observed nuclei contained about $40-60$ at. $\% \mathrm{Cu}^{26}$ Thus, these coherent bcc precipitates would form easily even at low temperatures. Hence, a considerable amount of coherent $\mathrm{Cu}$ precipitates should form during heating in the DSC. The nearest-neighbor distance of the bcc solid solutions strongly depends on the composition of the material (Fig. 1). Thus, the formation of coherent $\mathrm{Cu}$ particles with roughly $40-60$ at. \% $\mathrm{Cu}$ should be reflected by the NND. A distribution of nearest-neighbor distances for sample regions with different compositions would appear as a contribution to the measured atomic-level strain. In addition, the coherency of bcc $\mathrm{Cu}$ precipitates would give rise to a contribution of the elastic strain caused by the strain energy introduced by a coherent precipitate. ${ }^{27}$ Both effects would lead to an apparent increase, or at least no decrease, in the rms strain upon precipitation. However, the measured atomic-level strain of the bcc alloys decreases significantly upon heating to elevated temperatures [Fig. 5(c)]. Therefore, our data are inconsistent with the formation of coherent bcc $\mathrm{Cu}$ precipitates upon phase separation.

As an alternative to the formation of $\mathrm{Cu}$ precipitates, we suggest that the $\mathrm{Cu}$ atoms diffuse to the grain boundaries of the bcc Fe crystallites upon annealing, as suggested by the lower cohesive energy of $\mathrm{Cu}$ compared to $\mathrm{Fe}$. It is well known that the $\mathrm{Fe}$-Cu system exhibits a tendency for $\mathrm{Cu}$ segregation to grain boundaries. ${ }^{34}$ This agrees with our finding that the bcc NND seems to deviate more and more from Vegard's law with increasing overall $\mathrm{Cu}$ content. Hence, the bcc grain boundaries of the as-milled powders might become more $\mathrm{Cu}$ rich with increasing overall $\mathrm{Cu}$ content. Further grain-boundary segregation upon annealing would result in a microstructure where a bulk bec Fe grain is surrounded by a layer of almost pure $\mathrm{Cu}$. Such a microstructure has been confirmed by recent Mössbauer and electron energy-loss spectrometry investigations on bcc $\mathrm{Fe}-\mathrm{Cu}$ alloys, showing a rather thick $\mathrm{Cu}$-enriched grain-boundary layer of $\geqslant 1 \mathrm{~nm}$ thickness for isothermal annealing at $530 \mathrm{~K} .{ }^{21}$ This is consistent with the depletion of the bcc solid solutions in $\mathrm{Cu}$ during the first DSC exo- 
therm [Fig. 6(c)]. For this, $\mathrm{Cu}$ atoms from the grain interior must migrate to the grain boundary. Since the activation energy for $\mathrm{Cu}$ tracer diffusion in $\mathrm{Fe}$ is slightly larger than the activation energy for Fe self-diffusion, this does not occur before $\mathrm{Fe}$ atoms can also migrate easily. Thus, phase separation and grain growth occur simultaneously in bcc $\mathrm{Fe}-\mathrm{Cu}$ solid solutions.

Further grain growth of the bcc phase can only occur by migration of the $\mathrm{Cu}$ atoms at the grain boundaries, since the positive enthalpy of mixing for $\mathrm{Fe}-\mathrm{Cu}$ prevents resolution of $\mathrm{Cu}$ when the bec grains grow. This suggests that the $\mathrm{Cu}$ grain-boundary layer might grow and finally form small $\mathrm{Cu}$ grains, most likely at triple junctions between adjacent bec grains. Thus, small peaks of fcc $\mathrm{Cu}$ particles appear in the x-ray diffraction pattern for $\mathrm{Fe}_{95} \mathrm{Cu}_{5}$ powder heated to $720 \mathrm{~K}$ [Fig. 3(c)]. The measured activation energy of the second DSC peak for bec alloys which is characteristic for $\mathrm{Cu}$ self-diffusion and/or $\mathrm{Fe}$ diffusion in $\mathrm{Cu}$, indicates that both nucleation of $\mathrm{Cu}$ and grain growth of $\mathrm{Fe}$ occur simultaneously. Furthermore, the NND of the fcc phase in $\mathrm{Fe}_{95} \mathrm{Cu}_{5}$ powder heated to $870 \mathrm{~K}$ reveals that this phase still contains about 10 at. \%.Fe. Thus, the second exotherm for the bcc alloys seems to be related to coarsening of fcc grains and further phase separation which is not yet complete after heating to $870 \mathrm{~K}$. It is worth noting that $T_{2}$ of the bcc alloys decreases with increasing $\mathrm{Cu}$ content: The more $\mathrm{Cu}$ present in the as-milled powder, the sooner the grain-boundary layer might reach the critical thickness necessary for nucleation of a $\mathrm{Cu}$ particle. This would lead to a decrease of $T_{2}$ during constant-rate heating, as observed in our experiments.

With the segregation of $\mathrm{Cu}$ atoms to bcc grain boundaries one would expect that this effect might stabilize the material against grain growth. Grain growth of bec grains would eliminate grain boundaries, leading to redissolution of $\mathrm{Cu}$ into the bcc Fe-rich grains. This is unfavorable due to the positive enthalpy of mixing of $\mathrm{Fe}-\mathrm{Cu}$. Such a stabilization of the grain size has recently been reported for supersaturated nanocrystalline bcc $\mathrm{Nb}-\mathrm{Cu}$ alloys. ${ }^{35}$ This has been explained by a metastable equilibrium condition between the $\mathrm{Cu}$-rich grain-boundary phase and the lattice. Grain growth can only occur when $\mathrm{Cu}$ particles can nucleate at higher temperatures, as observed for our samples during heating to $720 \mathrm{~K}$. This reveals that the grainboundary layer grows beyond a certain thickness which is determined by the metastable equilibrium between the grain-boundary phase and the grain. Hence, no such stabilization of the grain size can be observed for our $\mathrm{Fe}-\mathrm{Cu}$ powders. Instead, the grain boundaries seem to thicken upon annealing and finally nucleate $\mathrm{Cu}$ particles. This might be due to the comparable diffusivities of $\mathrm{Fe}$ and $\mathrm{Cu}$ and the large positive enthalpy of mixing for the $\mathrm{Fe}-\mathrm{Cu}$ system in contrast to the slightly negative enthalpy of mixing for $\mathrm{Nb}-\mathrm{Cu}[+13 \mathrm{~kJ} / \mathrm{mol}$ for $\mathrm{Fe}-\mathrm{Cu}$ and $-3 \mathrm{~kJ} / \mathrm{mol}$ for $\mathrm{Nb}-\mathrm{Cu}$ (Ref. 18)]. Perhaps grain size stabilization can be better obtained for alloys with a smaller tendency for segregation, so that the energy cost of segregating atoms to grain boundaries is not so strongly overcome by the enthalpy reduction due to decomposition as for $\mathrm{Fe}-\mathrm{Cu}$.
However, some grain size stabilization has been observed in our experiments. Whereas the fcc grains in twophase $\mathrm{Fe}_{70} \mathrm{Cu}_{30}$ grow to $\sim 22 \mathrm{~nm}$ during heating to $870 \mathrm{~K}$, the fcc grain size in initially single-phase fcc $\mathrm{Fe}_{30} \mathrm{Cu}_{70}$ saturates at $\sim 19 \mathrm{~nm}$ and the fcc grains in single-phase bcc $\mathrm{Fe}_{95} \mathrm{Cu}_{5}$ only grow to $\sim 14 \mathrm{~nm}$. This is significantly smaller than the grain size in ball-milled nanocrystalline pure $\mathrm{Cu}$ of $\sim 31 \mathrm{~nm}$ after heating to $870 \mathrm{~K},{ }^{36}$ indicating that the presence of $\mathrm{Fe}$ atoms hinders the grain growth of $\mathrm{Cu}$. No such effect occurs for the bcc phase. Upon heating to 870 $\mathrm{K}$, the bcc grains in our powders grow to $\sim 21-24 \mathrm{~nm}$ for all samples. This is nearly identical to the value found for the grain growth in ball-milled nanocrystalline pure $\mathrm{Fe}$ $(d \sim 24 \mathrm{~nm}) .^{23}$ Thus, the presence of $\mathrm{Cu}$ atoms does not affect the coarsening of Fe.

\section{CONCLUSION}

We have shown that mechanical alloying of binary Fe$\mathrm{Cu}$ powder mixtures leads to the formation of highly supersaturated nanocrystalline $\mathrm{Fe}-\mathrm{Cu}$ solid solutions with grain sizes ranging from 2 to $20 \mathrm{~nm}$. Additions of $\mathrm{Fe}$ in single-phase fcc alloys improve the thermal stability of the fcc solid solutions compared to the stability of nanocrystalline $\mathrm{Cu}$. On the other hand, increasing the $\mathrm{Cu}$ content in single-phase bcc alloys does not significantly affect their thermal stability compared to nanocrystalline Fe. During heating to elevated temperatures phase separation and grain growth of the initially ultrafine powders occur. The grain growth behavior is determined by the microstructure of the samples. Single-phase solid solutions show nearly no grain growth but mainly strain release before phase separation sets in at elevated temperatures. In contrast, powders consisting of a two-phase mixture of fcc and bcc phases exhibit some grain growth and strong chemical redistribution even at quite low temperatures. Thus, the nucleation of a second phase hinders phase separation and grain growth in single-phase alloys. For two-phase mixtures this constraint is removed and decomposition and grain growth occurs more rapidly. The phase separation of single-phase fcc and bcc alloys seems to proceed via different mechanisms: fcc alloys decompose by formation of bcc $\mathrm{Fe}$ particles, while phase separation in bcc solid solutions proceeds via enrichment of $\mathrm{Cu}$ at bec grain boundaries, forming a grain-boundary layer of almost pure $\mathrm{Cu}$ before nucleation $\mathrm{Cu}$ particles. The presence of $\mathrm{Cu}$ atoms does not affect the coarsening behavior of the bcc phase in the Fe$\mathrm{Cu}$ alloys compared to pure nanocrystalline $\mathrm{Fe}$. On the other hand, the presence of $\mathrm{Fe}$ reduces the grain growth of the fcc phase compared to pure nanocrystalline $\mathrm{Cu}$.

The results reveal that the microstructure of nanocrystalline material strongly infiuences the stability of such ultrafine structures. However, much work remains to be done to understand the mechanisms governing the stability of these novel materials, and to obtain optimum microstructures for alloys with possible technical applications. 


\section{ACKNOWLEDGMENTS}

This work was supported by the United States Department of Energy under Contract No. DE-FG0386ER45242. Special thanks are given to C. C. Ahn, R. Birringer, P. Carpenter, B. Fultz, C. E. Krill III, and $\mathrm{H}$. Ouyang for stimulating discussions and effective cooperation.

'R. B. Schwarz and C. C. Koch, Appl. Phys. Lett. 49, 146 (1986).

${ }^{2}$ J. Eckert, L. Schultz, and K. Urban, Appl. Phys. Lett. 55, 117 (1988).

${ }^{3}$ E. Hellstern, H. J. Fecht, Z. Fu and W. L. Johnson, J. Appl. Phys. 65, 305 (1989).

${ }^{4}$ H. J. Fecht, E. Hellstern, Z. Fu, and W. L. Johnson, Adv. Powder Metall. 1, 11 (1989).

${ }^{5}$ J. S. C. Jang and C. C. Koch, Scr. Metall. Mater. 24, 1599 (1990).

'J. Eckert, J. C. Holzer, C. E. Krill III, and W. L. Johnson, Mater. Sci. Forum 88-90, 505 (1992); J. Mater. Res. (to be published).

${ }^{7}$ J. Eckert, R. Birringer, J. C. Holzer, C. E. Krill III, and W. L. Johnson, in Structure and Properties of Interfaces in Materials, edited by W. T. Clark, U. Dahmen, and C. L. Briant (MRS, Pittsburgh, PA, 1992), Mater. Res. Soc. Proc. Vol. 238, p. 739.

${ }^{8}$ J. Eckert, J. C. Holzer, C. E. Krill III, and W. L. Johnson, J. Mater. Res. 7, 1751 (1992).

${ }^{9}$ J. Eckert, J. C. Holzer, C. E. Krill III, and W. L. Johnson, J. Appl. Phys. (to be published).

${ }^{10}$ T. B. Massalski, Ed., Binary Alloy Phase Diagrams, 2nd ed. (ASM International, Materials Park, OH, 1990), p. 1408

"K. Sumiyama, T. Yoshitake, and Y. Nakamura, J. Phys. Soc. Jpn. 53, 3160 (1984).

${ }^{12}$ C. L. Chien, S. H. Liou, D. Kofalt, W. Yu. T. Egami, and T. R. McGuire, Phys. Rev. B 33, 3247 (1986).

${ }^{13}$ W. Klement, Jr., Trans. AIME 233, 1180 (1965).

${ }^{14}$ F. Kajzar and G. Parette, J. Appl. Phys. 50, 1966 (1979).

${ }^{15} \mathrm{G}$. Longworth and R. Jain, J. Phys. F 8, 351 (1978).

${ }^{16} \mathrm{~K}$. Uenishi, K. F. Kobayashi, S. Nasu, H. Hatano, K. N. Ishihara, and P. H. Shingu, Z. Metallkde. 83, 132 (1992).

${ }^{17}$ A. R. Yavari and P. J. Desré, in Ordering and Disordering in Alloys, edited by A. R. Yavari (Elsevier, London, 1992), p. 414.
${ }^{18}$ A. K. Niessen, F. R. de Boer, R. Boom, P. F. de Châtel, W. C. M. Mattens, and A. R. Miedema, CALPHAD 7, 51 (1983).

${ }^{19}$ H. P. Klug and L. Alexander, X-ray Diffraction Procedures for Polycrystalline and Amorphous Materials, 2nd ed. (Wiley, New York, 1974), p. 661.

${ }^{20}$ U. Herr, J, Jing, U. Gonser, and H. Gleiter, Solid-State Commun. 76, 197 (1990).

${ }^{21}$ C. C. Ahn, L. Hong, J. Eckert, B. Fultz, and W. L. Johnson, Energy Filtered Imaging of Nanophase Materials, edited by G. W. Bailey, J. Bentley, and J. A. Small (San Francisco Press, 1992), pp. 1196-1197.

${ }^{22}$ K. Sumiyama, Y. Yoshitake, and N. Nakamura, Acta Metall. 33, 1785 (1985).

${ }^{23}$ J. Eckert, R. Birringer, J. C. Holzer, Carle E. Krill III, and W. L. Johnson, J. Mater. Res. 238, 739 (1992).

${ }^{24}$ H. E. Kissinger, Anal. Chem. 29, 1702 (1957).

${ }^{25}$ C. J. Smithells, in Smithells Metals Reference Book, 6th ed., edited by E. A. Brandes (Butterworths, London, 1983), p. 13-9.

${ }^{26}$ S. R. Goodman, S. S. Brenner, and J. R. Low, Jr., Metall. Trans. 4, 2361 (1973); 4, 2371 (1973).

${ }^{27}$ E. Hornbogen, Acta Metall. 10, 525 (1962).

${ }^{28}$ E. Hornbogen and R. C. Glenn, Trans. J. Metals. AIME 218, 1064 (1960).

${ }^{20}$ J. B. Newkirk, Trans. J. Metals AIME 209, 1214 (1957).

${ }^{30}$ J. M. Denney, Acta Metall. 4, 586 (1956).

${ }^{31}$ B. Windrow, Philos. Mag. 26, 681 (1972).

${ }^{32}$ K. A. Gschneidner, Jr., in Solid State Physics, edited by F. Seitz and D. Turnbull (Academic, New York, 1964), Vol. 16, p. 275.

${ }^{33}$ D. A. Porter and K. E. Easterling, Phase Transformations in Metals and Alloys (Van Nostrand Reinhold, London, 1981), p. 137.

${ }^{34}$ E. D. Hondros and M. P. Seah, in Physical Metallurgy, 3rd ed., edited by R. W. Cahn and P. Haasen (Elsevier Science, Amsterdam, 1983), p. 865.

${ }^{35}$ Y. R. Abe, J. C. Holzer, and W. L. Johnson, in Structure and Properties of Interfaces in Materials, Mater. Res. Sco. Proc. Vol. 238, edited by W. T. Clark, U. Dahmen, and C. L. Briant (MRS, Pittsburgh, PA, 1992), p. 721.

${ }^{36} \mathrm{~J}$. Ecker (unpublished results). 